\title{
Research on the Enlightenment of "Monk Sha Spirit" Adhering to the Rule Is the Only Way Leading to Constitutionality \\ Le Che ${ }^{1, \text { a }}$ \\ ${ }^{1}$ Xi'an Beilin District People's Court, Xi'an, Shaanxi, China, 710006 \\ ${ }^{\mathrm{a}}$ email,
}

Keywords: "Monk Sha Spirit", Hold Fast, Rule, Constitutionality

\begin{abstract}
Through the narrative of phenomenon that does not comply with the rules in the society, the paper promotes the social problem: When the social rules conflict which the social and personal values, which one should actually prevail? Then, the writer uses the "Journey to the West" to analyze the negative factors and positive quality hidden in humanity, which leads to the spirit of this article, "Monk Sha Spirit", that is maintaining compliance with the rules. Next, the author combines the traditional culture such as the thought of Lao $\mathrm{Zi}$, the thought of Kong $\mathrm{Zi}$, the thought of Wang Yangming to sum up the internal relations of traditional culture and the spirit of the Monk Sha and analyze the substance of the sticking to spirit, explain the relationship between moral ideas and moral behavior and get the conclusion: we should achieve moral ideal by complying with reality ethical behavior. Then, the author analyzed why it is not easy to form the rules of atmosphere in our country. Finally, the authors propose the major theme that adhering to the rule is the only way leading to the constitutionality and reaffirmed the important revelation of adhering to the rules in today's environment.
\end{abstract}

\section{The Embarrassing Territory of the Rule}

In March 2016, the network video section gets heat transfer in which the Sanya City police enforcement was asked to show their law enforcement certificates. At $5 \mathrm{pm}$ on March 22, near Sanya Railway Station, the designated driver of a 50-year-old man who suspected of drinking, drove a van into the bus lane, traffic police then approached to correct their behavior, and requested check the driver's license and driving permit. The man immediately asked the parties to show the permit the police law enforcement, police said police dressed in police uniforms can confirm their identity and produce enforcement certificates, but the man refused to cooperate with law enforcement. Later, due to a serious impediment to the man vehicle traffic three hours, police forced their uniforms, this man was someone's obstruction of official duties in administrative detention on the 10th, it was reported that the man was a retired court judge. "Policemen use permit regulations" (Ministry of Public Order No. 81) in the fourth clear: the people's police certificates are policemen from performing their duties and identity documents and signs. In other words, the police in carrying out their duties, showed police identity card and show police procedures comply with the law, law enforcement does not have to produce a separate license. The man also be familiar with the legal professionals, he knows how to make full use of legal weapons to protect their interests, but at the same time he questioned whether the identity of the police officers also think about their own behavior has a serious traffic jam in violation of traffic laws and social order. Similarly, a recent Shanghai lawyer in Shanghai Bao'an District Court filing requirements when the value of the judge to show the judge evidence, and call 110 in the filing room asked police to deal with this "posing as a judge," this scene so that all those present were stunned. In our usual judicial work, and often we found that some unscrupulous parties loudly shouting, there is no bottom line farce, and even the injury to the judiciary. If the judiciary cannot maintain the order, the court can not comply with the rules, who would adhere to the rule of the whole society? When the social rules conflict which the social and personal values, which one should actually prevail? 


\section{Analysis Human Nature from the Journey to the West}

At the beginning of analyzing this question, I would like first to talk about humanity. Discussion of any kind of social phenomenon is inseparable from the analysis of human nature, because society is composed of individuals, and the event is the result of human nature driven. A departure from this premise, the research work will lose direction and meaning. However, human nature is too complex, too abstract, in particular, in reality there are too many bizarre phenomenon, it is difficult to grasp, so we are still looking for answers from plain fiction. "Journey to the West" is one of the Chinese four masterpieces of the most well-known mythical novels. Why does this work can be so popular? I think the "Journey to the West" is written mythical on surface, in fact, it writes the people.

"Journey to the West" is a novel about Buddhism, many people think that Buddhism is a religion, but I tend to Buddhism as a philosophy to study. This is the philosophy when talking about human nature that "greed (craving), anger (angry), ignorance (ignorance)" are the three basic evils of people, called the "three poisons." Greed - is a persistent desire; anger - for joy, anger, paranoia; crazy - for like paranoia, is a fundamental duffers. Purpose of Buddhism is to reduce this to eliminate the three poisons. We go back to work in the analysis, a household knows best original image than the Tripitaka, Monkey, Pig and Sha Monk. In particular, these three looks weird, like people inhuman apprentice is to be won public recognition and love. Monkey ridicule, ignition on, pull the stick to the opposing character is representative of "angry"; Pig greedy, lusty, greedy, greedy personality represents a "greedy"; Sha Monk of the ordinary stands for "crazy." Historically, Buddhist sutra is basically completed by Xuanzang, as a person, whether attached to the "Primary Afflictions" nature of Xuanzang? The answer is definitely yes!

We analyzed the three negative factors of human, now we analyze the humanity three active levels again from another perspective. Although the Monkey King has angry side, but he is evil, fear the strong spirit also represent a valuable human quality - courage; say Pig lazy, greedy, but his feelings, Xiao human, still be able to come forward at the crucial moment out. Three drugs in the "greed" is also called "craving", greed and love are closely linked, and this is the second valuable human quality - love. Sha Monk is the most simple, the most obscure, seemingly the least merit in this team, but he is also the team's staunchest faith people. This is the third human valuable quality - stick to the faith!

In $627 \mathrm{AD}$, Xuan Zang opened his magnificent westbound way to get the law. He faced with extremely dangerous things, it is by virtue of the kind of extraordinary courage as (Goku spirit) and to human love (Journey spirit) to be completed. In addition, it relies on the hearts of over persistent insistence on rules and prohibitions tireless stick (Monk Sha Spirit). When Xuanzang went to congratulate Mo Yan moraine eight hundred years in the desert, since accidentally knocked over a water bag, Xuanzang and his horse has not dripping soiled for five days. He faces two choices: go forward, never got water in quite a short time and then he would die; go back, he can go to the inn supplies, may greatly increase opportunities for students, but will also learn to be killing; in the end go from here ? Then he thought of standing vow before westbound: "' I would rather die further to the west, not east soil half a step further, "he quietly told himself:." I for the sake of law and is willing to homes footer life, I've already established under the rules only west, and never the East also, even if lives were lost in this, and never regret it! "He remained true to his promise, taking firm steps to move on. Miracle occurred and he led his horse to find an oasis.

This is the spirit that is - stick to the faith. Kennedy is the firm conviction, to keep the rules as his ideal and maintain compliance with the rules!

\section{Monk Sha Spirit and Traditional Culture}

Monk Sha Spirit and the Thought of Lao Zi. Lao Zi think "of charity", people should pay attention to water Germany, in fact, you can follow the shape of the external environment to change their shape, but essentially nothing to prevent water and hung its large far-reaching. This is the interpretation of the Monk Sha spirit stick looks certainly not so spectacular, sometimes even felt a little ordinary, even commonplace, but this does not deny the extraordinary humble hearts have 
ambition, on the contrary this is a big humility wisdom. The behavior of Monk Sha is often seen as one kind of mediocrity, submissive ordinary person, but behind him hidden goals to complete the pilgrimage and the pursuit of big ideals of Dharma!

Monk Sha Spirit and the Thought of Kong Zi. About the thought of Kong Zi, in terms of concentrate is the word "benevolence" and "ritual."

Kong $\mathrm{Zi}$ told people the relationship between ethics and moral purpose of deconstruction, value judgments beyond dreams and down to earth. This is also what I call the spirit of Monk Sha, Monk Sha pulled horse per day (in the original Journey to the West Monk Sha is mainly responsible for the horse, Journey primarily responsible for the child knows the weight) acts mostly procedural, does not matter good or bad. But if one day Monk Sha not does these procedural matters, it will inevitably lead to disorderly learn to work (if not Monk Sha, who is going to pull horse? Monk Sha took over the work of people how to do their jobs? Future team members can do not act according to the division?), learn the impact goals and once the program is in violation will strongly react against the entity. Therefore, to achieve high ethical standards must comply with the specific norms, agreed to start the program execution.

Monk Sha Spirit and the Thought of Wang Yangming. The core idea of Wang Yangming is "Knowledge and Action" and "To conscience." The so-called unity of knowledge is not a simple theory with practice, the main idea is to highlight the moral and ethical conduct relations, highlighted the moral attributed to all individual initiative. Moral awareness and moral consciousness of the inevitable manifestations of moral behavior, if they do not act, cannot be considered true knowledge, if not contrary boot true knowledge, action loses moral sense. Truth of the origin of man and of the conscience, the "Knowledge and Action" is "the Conscience." Wang Yang Ming said: "Knowledge is the line's idea, the line is known to work; knowledge is the beginning of the line, the line is known as." Means that the person is the guiding ideology of moral behavior, to act in accordance with the requirements of morality is to achieve "conscience" of the time. Activities under the guidance of moral ideas are to start generating behavior, ethical behavior is required "conscience" is completed.

By combining our traditional culture to analysis the spirit of Monk Sha, we find that these are the cultural connotation explains how to handle the relationship between moral consciousness and moral behavior. Common conclusion is: the holy people care about the real rules of conduct, consistent with the rules of human behavior naturally in line with the ethical standards! Mr. Hu once said: "a dirty country, if everyone tells the rule rather than talk about morality, eventually someone will become a normal country taste, moral nature will gradually return; a clean country, if everyone the rules do not speak, but to talk about morality, about noble, every day, all right to talk about ethics, all selfless, and ultimately the country will degenerate into a dirty country full of hypocrite."

\section{Why Is It So Difficult to Adhering to the Rules?}

In our real life, there are even those who regarded breaking the rules as a kind of wisdom, success and even glory. I think there are many factors for this.

Privilege Precipitation. There are many privilege thought were reflected from the ancient legal system in China, the Han Dynasty, aristocratic officers guilty of "first call" (Emperor consult award) edict, please all the scriptures, are generally required to obtain a commutation or pardon. Many privilege have followed to the Qing system. So that in the modern democratic society, although there is no written law of the privilege, but there will be many privileges precipitation down. Privilege is not terrible and the most terrible is this privilege thinking becomes a deep unspoken rule in every corner of society and into people's bone marrow.

Trickery Utilitarianism. In Chinese traditional values, it has Machiavellian utilitarian and the winner takes undercurrent. In history of the world, if analyzed according to the proportion of the population, the most of the killings occurred in a war in China. This war is called "Shi Rebellion," which caused the deaths of 36 million people (if calculated according to the proportion of our population is 420 million now). However, the incredible is that many people did not go to sympathize with the weak, there is no real justice to torture, but that interest is to achieve success, if 
success in this process can play with the rules were seen as a manifestation of wisdom. This will get the Machiavellian core thinking is: for power and interests we can have no bottom line! How to respect the rules of society if a person has not the bottom line?

Human Society. The tendency of Western Philosophy is major natural or human origin and nature of the relationship, our philosophy focuses on the ethical relationship between people. By the profound influence of Confucianism, our country has always been focused on ethics, emphasis on human cultural traditions. It should be said this tradition within a certain range of interpersonal enhanced mutual trust between people, mutual love and warmth will inevitably have a positive side. Because when we value judgments, non-obvious choice easier for us, but there are two that we have recognized the value exists, it is a more difficult task. The second session of the CPPCC National Committee meeting of the third plenary session of the CPPCC National Committee, Democratic National Construction Association, vice chairman of the Shaanxi Provincial Committee Zhou Xinsheng entitled "trying to keep people asking for help," the report won the praise of many people, from it also shows that China is still in a stage of human society.

The Slavery Mentality. The reason of many people do not follow the rules is that the rule represents slavery mentality. Take Monk Sha for example, many people look down on this role because that he cannot hack it and he has no merit. However, by reading the original, you will find Monk Sha is also the only team never wavered learn beliefs. Although the daily work of the master, Big Brother, but if any of them wanted to shake the Buddhist sutras to pursue broad principles, big ideals of Buddhism, he is bound to come forward and firmly opposed. Not adhere to the spirit of servility and the former is only responsible for the rules, whereas the latter is subject to a monarch, boss or spiritual power.

Unknown Incentive. Life, we often meet pedestrian red light phenomenon, a large number of passenger shuttle in traffic, it touches on a very small number of people stood waiting for a red light exceptionally special, heterogeneous became public eye, it has become the "red light proud to red light ashamed. " This way, people do not follow the rules of recognized others who violate the rules there is no corresponding penalties but gained praise and interests. We mentioned the parties in court shouting, and even attack the judge, and why this situation has become the norm in the law? Too many facts have proven that for some so-called big picture, these people often lack discipline, not only that but also get the benefit of some overjoyed. Over time, everyone followed suit, can benefit from this logic, the court order will inevitably become waste paper and the judicial system will inevitably lose authority!

\section{The Road Leading to the Constitutionality - To Adhere to the Rules}

When the rules are the rules, people will use the rules to protect the freedom and this is the most fundamental rules of the highest significance. This freedom includes the freedom to grow freely, development potential, to solve the problem of free, responsibility, and freedom of the answer. The constitutionality is the rule of the rules, do not ask who you are, unconditionally abide by the rules, above the law and nothing else; the rule of man is the prerogative of the government, even if the rules have to apply to see who to whom applicable law will become a vassal. But how to make most people stick to rules?

Forming the Vision of Individual Motivation. Front Watergate described and examples of Song officials gave us a revelation that society needs a large number of "worry first thing in the world and worry, after the world is happy," the lofty ideals they uphold the hearts of justice with their lives stick with rules and norms. In the crucial Watergate law enforcement, if there is one factor outside the system shaken, we believe that the United States would rewrite history. Therefore, society needs a large group of people to maintain the system, creating a culture of respect for the rules. However, a short step a thousand miles, no small streams into a mighty torrent that consists of a large group of people also needs small individual components. From each of us personally, we must adhere to the rules of the formation of consciousness. Of course, to do anything, there will be a certain degree of motivation, the rules will have motivation, but this motivation does not depend on talk theory, do mobilization can be done overnight, it should be the motivation to rise to the 
vision (vision that is longing for the scenery, it is a people long-term goal, mission, over) levels. This vision of motivation called sense of responsibility, namely the state and the society, is responsible for all living things. About this responsibility vision, Wang Yangming which is called the conscience, a sense of responsibility itself rooted in our hearts, and people grow up a little bit to take root. We rely on the responsibility of vision obtained the meaning of life, relying on the rules to make people a psychological, spiritual and even a dignified posture on people.

Don't Shouting Empty Slogans and Do More Specific Things. To do adhere to the rules must be less shouting empty slogans and do more specific things. I think, is specifically dedicated patriotism, everyone quietly do a good job, our country will naturally be better, Chinese dream will come true! Judge for occupations, it is more specific, the write judgment is patriotic conscience. Every day we call the constitutionality, constitutionality and then what is the constitutionality? Everyone respected the constitutionality is procedural; the constitutionality is a violation of the rules when we feel shame; the constitutionality is that we no longer jump the queue to buy something; the constitutionality is not to let his subordinates leading travel bag; the constitutionality is no longer on the hospital patient acquaintances; the constitutionality is only responsible for writing the law judge's decision, regardless of whether a certain satisfaction.

Firstly, Comply With; Secondly, Rethinking. This article was originally referred to Sanya that were blocking traffic on behalf of men in society there is a person: When a rule in their favor, they use rules; when the rules are not in their favor, they challenged the rules, contrary to the rules. First thing to say is that I am not against the law to reflect the system, institutional rules have always been good and bad, some of which should be modified. But this program is needed, not in order to deny a person's subjective judgment. That is, we are bound to comply with the rules of good, even the bad rules when we modify without due process must be followed. In all cases, nothing more than the death of Socrates touched our hearts up. On the other hand, if we go to discuss the good or bad legal provisions and not to comply with it, this will result in good rule might be abandoned, disorderly society and the legal system will become a tool to achieve the interests, into a pile of any trampled waste. Therefore, we must first comply with the rules of the face, and then reflect on!

\section{Conclusion}

My understanding of the "constitutionality" is anything should be scheduled to solve in accordance with the objective rules in advance, rather than by subjective will to solve afterwards (whether the subject of the will is the individual or collective). This may be a long road, we might slack off and anxious in the road, but as long as we remember the responsibility over the shoulders, we will not feel lonely and confused and courage us to move on.

\section{References}

[1] Xuanzang, Rui Chuanming. Buddhist Records Complete Translation [M] Guizhou: Guizhou People's Publishing House, 2008, 46

[2] Yang Lin. Illustrates the Moral [M] Beijing: People's Publishing House, 2013, 92

[3] Wang Shen. Behavior [M] Xi'an: Shaanxi Normal University Press, 2014,121.

[4] [US] Steven Pinker, Anwen translation. The human nature good angels [M] Beijing: CITIC Publishing House, 2015,232.

[5] Li Ming. Western philosophy is dead [M]. Chinese Workers Publishing, 2003 (12)

[6] Gao Guoxi. The moral philosophy [M] Shanghai: Fudan University Press, 2005,164.

[7] Plato. Plato Collection (Volume I) [M]. Beijing: People Publishing House, 2012, 49. 